\title{
Immersion and Identity: \\ Experiences of an African American Preschool Child
}

\author{
Ruanda Garth McCullough \\ Loyola University Chicago \\ U. S. A. \\ Sharon Adelman Reyes \\ DiversityLearningK12 \\ U. S. A.
}

This article explores the benefits and challenges of a Spanish language immersion preschool from the perspective of a non-Spanish speaking African American family. Data explored include the decision to enroll, reactions from peers and family, home-school communication issues, language development, and family involvement. In addition, recommendations for families considering this bilingual option are considered. The primary data used for this article come from 127 journal entries written by the mother of the child from the beginning of the preschool admissions process until the end of preschool.

\author{
The Decision \\ The Reactions \\ The Transition to Preschool \\ The Waiting Game \\ Language Development \\ Recommendations \\ Conclusion \\ Notes \\ References
}

The experience of sending an African American child to a full-day Spanish Immersion Montessori preschool had many challenges and rewards. In the following article, the first author's journal entries detail her family's experiences throughout the process. While the transition into preschool was relatively smooth, the slow progression of language development, coupled with the language barrier issues that affected home-school communication, fueled the questioning of the decision. The journey included struggles with the limited ability to support her daughter Joyce Lynn's ${ }^{1}$ language development. Once more Spanish language activities were integrated into the family life, her family started to witness evidence of learning. Yet, despite some misunderstandings and unrealistic expectations throughout Joyce Lynn's first year in preschool, by the 
end of the year her family was pleased with the outcomes of her Spanish immersion experience in terms of both language and identity.

The data used for this article come from the first author's journal entries from the beginning of the preschool admissions process in January 2006 until the end of the summer after Joyce Lynn's first year in preschool in August 2007. The journal is written from the perspective of the first author, an African American mother of an African American child, whose family resides in a large metropolitan area. The author made entries in the journal each time there was a significant event related to the school decision, admissions, enrollment, and attendance. The journal entries also included observations of, as well as interactions and conversations with, school officials, other parents, her spouse, and daughter. The completed journal was composed of 127 entries. The article is written in the voice of the first author although it combines the writing and research of both authors.

\section{The Decision}

The decision to enroll Joyce Lynn in a Spanish-immersion Montessori preschool was sparked by my prior experiences with the benefits of foreign language instruction from as early as $2^{\text {nd }}$ grade. In 1980 I attended a bilingual magnet program for German language instruction at my neighborhood public school. The lessons I learned from the unique backgrounds of my teachers and extracurricular experiences helped shape my worldview.

Unfortunately, as I matriculated through the magnet program, my language instruction became more frustrating. I had not developed an accent; my vocabulary level was primary at best, I was not enjoying the content, and I did not see a use for the language I was learning. This same trend was found in a study of African American students learning German at a Historically Black College (Rankin, 1998). My husband and I wanted Joyce Lynn to begin learning a second language early and in a more authentic way than I had to ensure that she would become fluent. $\mathrm{We}^{2}$ also wanted to encourage her development of bilingual/bicultural attitudes. Although our home environment would be the primary source of her cultural identity, we understood that the school we chose would play an important role.

I was encouraged by the research that indicates the positive long-term cross-cultural attitudinal effects from students who have experienced the immersion approach (Collier, 1989). My exposure to other cultures through language has taught me the importance of a global worldview, which fueled my desire for my daughter to be able to fully participate in our global society. We chose Spanish as the language our daughter would learn in preschool because of its relevance and utility in the United States and abroad. We thought that my husband's Spanish-speaking ability was at a level sufficient to support Joyce Lynn's initial language development. Since some bilingual models suggest that an individual's sociocultural, linguistic, academic, and cognitive development is 
linked as interdependent processes (Collier \& Thomas, 2000; Adelman Reyes, 1998), we felt this would work to Joyce Lynn's advantage. Collier and Thomas (2000) note that in "students who come from a bilingual community...nonstop cognitive, academic and linguistic development...must occur in a supportive socio-cultural environment through their first language and their second language to enhance student learning" (p.1). Our expectation was that we would have access to a broad system of support, exposure, and opportunities for Joyce Lynn to develop her Spanish communication skills and attitudes.

\section{The Reactions}

In the immersion program at Shady Lane, Spanish is used not only for language instruction but also for delivery of subject matter classes at a preschool level. The use of the second language as a medium of instruction is one of the most distinguishing features of immersion education (Dolson, 1985). When we shared our decision to enroll Joyce Lynn in a Spanish immersion preschool, we encountered a mix of reactions, from supportive and inquisitive to unquestionably negative. We had optimistically assumed that most people we knew would share our recognition of the social and academic advantages of being bilingual and the positive effects of an immersion program (Giacchino-Baker \& Piller, 2006).

We received many questions referred to Joyce Lynn's ability to learn any content if she did not understand the language that the teacher was speaking. I tried to explain that language could be acquired, rather than learned, in a context-embedded classroom. I also attempted to convey that research supports native English speakers' participation in bilingual immersion classroom experiences (Collier \& Thomas, 2000; Howard, Sugarman, \& Christian, 2003; Lindholm-Leary, 2005). In terms of academic outcomes, longitudinal studies and smaller scale studies report that students enrolled in two-way immersion (TWI) programs perform as well or better than students enrolled in other types of programs on standardized achievement assessments (Ajuria, 1994; Castillo, 2001; Cazabon, Lambert, \& Hall, 1993; Coy \& Litherland, 2000; Gilbert, 2001; Kirk Senesac, 2002; Lindholm \& Aclan, 1991; Sera, 2000; Stipek, Ryan, \& Alarcón, 2001). Lindholm-Leary (2005) found that students in TWI programs consistently demonstrate higher levels of achievement than their peers in monolingual programs. Understanding that culture affects the learning process in language education classes, our plan was to support Joyce Lynn's ethnic identity while exposing her to other cultures and discourses. We tried to convey that too often African American students do not have opportunities to participate in language education classes, which leads to an educational deficit compared to their counterparts by the time they reach college (Moore \& English, 1997; Stewart \& Talburt, 1999). 


\section{The Transition to Preschool}

We considered six schools, but the climate at Shady Lane matched our social and academic expectations. Its blend of the best aspects of a Montessori environment with traditional preschool learning centers made for a colorful, engaging, and active classroom. The site with the Spanish language immersion program option for 3-year-olds housed only two mixed-aged classrooms. Each classroom of 18-20 students had one teacher and one teacher assistant, which would increase the opportunity for individualized attention.

In the Spanish classroom we observed that, of Joyce Lynn's 17 future classmates, five were African American, three were Latino, and one was of Asian descent; the remaining students were of European American descent. Six of the students spoke a language other than English at home, and Spanish was the first language of three of the students. As a child from a linguistic majority background, we felt that Joyce Lynn would be in a setting ripe for the development of both positive cross-cultural attitudes and identity (Adelman Reyes \& Vallone, 2007). While we were concerned about whether or not she could adapt to being in the linguistic minority, we believed that the immersion setting could develop her comfort in two worlds, she could learn lessons about contextually appropriate behavior, and she would have many opportunities to make sense of issues of race, language, and culture (Fernandez, 2006; Adelman Reyes, 1998).

In my effort to expose her to what Shady Lane would be like, I began to record the all-Spanish version of her favorite television character at the time, Dora the Explorer. Her response was a little troubling; when she watched the show, she began to cry. She said she did not know "what they were talking." I wonder if she will be this frustrated in school (Journal Entry, July 23, 2006).

In that moment of doubt, one thing that helped was remembering a clip from a video that I watched at another immersion school where a child who was fluent in the target language (the language of instruction) translated for another child during a class session. Bilingual immersion preschool classrooms have a high ratio of classroom activities in the target language, often $80 \%$ to $100 \%$ at the pre-kindergarten level (Adelman Reyes \& Vallone, 2007). Yet, the social context of learning is tapped to help all children succeed linguistically.

\section{The Waiting Game}

Despite the smooth transition, home-school communication issues became problematic during the first few months of the school year. After a few weeks, I began to worry when Joyce Lynn did not or could not tell me what she did in school. We were not sure if this was a function of being in an immersion program or if this was a common occurrence in a 3-year-old's transition to 
preschool. We decided to turn to Joyce Lynn's teacher, Ms. Marta, a Native Peruvian, for more information, but she was not confident in her use of English. Whenever I asked her how Joyce Lynn was doing, she would respond that Joyce Lynn was doing fine and comment on what a nice child she was. Our interactions and contributions were challenged due to the limited nature of the home-school connection (Ada, 1993). However, this served as a reminder of what our daughter might be experiencing in the classroom.

We went to Curriculum Night this evening. I was excited to learn more about their approach and the learning activities. Ms. Marta spoke Spanish throughout her entire presentation while the director translated. I am beginning to wonder if her English speaking skills are the reason she doesn't talk to me more during pick-up. There was no mention of their approach for the immersion classroom. I was quite disappointed. (Journal Entry, September 27, 2006)

Just as I was gaining empathy for children who were learning in their second language, I was also developing an understanding of what language minority parents might experience when they interact with their children's teachers.

I understood the research that demonstrates the importance of parentteacher relationships in creating positive experiences and outcomes in preschool. We were working at a disadvantage due to my lack of language proficiency (Knopf \& Swick, 2007). We were unsure about whether Joyce Lynn was hanging on tightly to the idea that school was her space and she did not want to grant us access, or if she was experiencing the silent period commonly referred to in second language acquisition theories (Krashen, 1997; Postovsky, 1974; SavilleTroike, 1988).

Every day on the car ride home, I would try different ways to get her to tell me what she did at school. Her responses ranged from, "Nothing," "I don't know," "I don't remember" to crying. Yet, I knew that if this was an instance of a silent period, she might be unable or unwilling to communicate in Spanish for up to a year (Krashen, 1997).

We began to develop some doubts about whether we had made the right decision for her academically when we did not see any evidence of academic learning. Our doubts were heightened when we compared her academic development to our friends' children who seemed to know more about letter recognition and other academic concepts than she did at the same age or younger. We weren't sure if the issue was with the Montessori approach, immersion, or a combination of both.

In fact, my anxiety was unwarranted. Research on immersion programs demonstrate that while it takes 5-6 years for a child to reach the $50^{\text {th }}$ percentile of language proficiency in the second language, there are no negative effects to native language development or academic achievement (Giacchino-Baker \& Piller, 2006; Thomas \& Collier, 2002). In addition, I began to question whether skills such as letter recognition were the only meaningful measures of cognitive 
development, and if they were necessarily developmentally appropriate.

Another concern was that Joyce Lynn's experience of the discrepancies between home and school could cause conflict in her educational development and identity formation (Ada, 1993). In terms of the language support we could offer, we were limited to speaking basic Spanish, reading in Spanish, and offering Joyce Lynn a limited exposure to Spanish television. In their study of parents of kindergarten and first grade children in a (two-way) immersion program, Giacchino-Baker and Piller (2006) found that the Spanish-speaking parents reported that they provided much more support than the English-speaking parents.

It was hard to know what we should be doing to support this process. She is three years old and doesn't read yet, so the Spanish-English dictionary I bought doesn't help. Most of the tapes and videos I have gotten follow the translation model, which is not how she is learning at school. Because my vocabulary level is low, I am unable to give her authentic language experiences like she is exposed to at school. My fear is that I will teach her poor speaking habits, like when I kept saying No en la boca the wrong way. (Journal Entry, November 20, 2006).

My fear that speaking to my daughter in Spanish could do more harm than good was actually well founded. Studies of students in one-way immersion programs (in which the only native speaker of the target language is the teacher) have uncovered patterns of fossilization, the grammatically incorrect use of the second language that is continuously repeated and becomes ingrained in speech patterns, in student discourse (Swain \& Lapkin, 1981). This is due to the repetition of grammatically flawed language as it is recycled throughout the classroom. Similarly, Adelman Reyes (1998) notes in her dissertation that her own daughter, a Spanish language learner and the subject of a language study, understood the difference between native and non-native speakers. It was not uncommon for her to correct her mother's Spanish grammar, syntax, and pronunciation. Joyce Lynn's separation between home and school language was prominent. This is consistent with Fishman's (1971) supposition that separation of language use by domains ensures bilingualism.

It was not until late October that we witnessed Joyce Lynn using Spanish. During the Halloween breakfast function, each class sang a song. I noticed that Joyce Lynn sang every word and did each movement. This was evidence that she was moving from the silent/receptive or preproduction stage to the early production stage of language acquisition (Krashen, 1997).

During the first teacher conference session in late November, we received feedback about Joyce Lynn's progress but had to request guidance about how to best support her language development. Ms. Marta went down a checklist of age-appropriate competencies that she had used to rate Joyce Lynn's abilities. My husband and I were pleased with her abilities, some of which we were learning about for the first time. 
Towards the end of the conference I realized that the teacher had not included anything about language development, so I inquired. I also asked a follow-up question about how we could support Joyce Lynn's learning at home. Ms. Marta began to tell us how Joyce Lynn learns a lot of language from the songs she plays in class and suggested that we do more Spanish speaking activities outside of school. We followed her advice and began to infuse activities from our collection of Spanish language children's books, games, and music into our family time.

\section{Language Development}

After we began to introduce Spanish language activities at home, we slowly began to witness evidence that Joyce Lynn was gaining confidence in her ability to share her developing Spanish language skills. We began to play the CD in the car that she received from her teacher for Christmas and listened to her sing along. But, whenever we asked her what she was saying, she would shut down. It was not until February that I heard her say a full sentence in Spanish.

I knew she was gaining confidence when she began to correct our pronunciation when we played games and read her stories. After awhile she would choose to count or tell me the color of an object or the name of an animal in Spanish. Joyce Lynn was not learning her second language; she was acquiring it. It was important to celebrate her accomplishments without shining a spotlight on them for fear that she would retreat behind the wall she had built up between school and home.

By spring, our daughter was identifying and celebrating herself as a Spanish speaker. But then I began to notice the pride that exuded when she made reference to her class membership. It was as if she felt bad for the students whose instruction was "English only." I interpreted that as a positive sign that she was comfortable and felt special. However, I became worried when I thought her exposure to the language was affecting her racial identity.

"I want a Spanish family mommy." That is what Joyce Lynn told me last week when we were out to dinner as she watched a Latino family leave the restaurant. I was surprised because she had never made reference to race or ethnicity before. I couldn't believe it. All week I have been obsessing over questions; Is she not picking up on our celebrations of our culture? What messages is she getting about ethnicity? Is it something in her school experience that is making her feel less worthy as an African American? For days she told me that she wanted to be in a Spanish family. She didn't let it go. I tried to point out the people in our family that speak Spanish, but that was not enough for her. Finally, today she put my racial concerns to rest when she said, "I don't want to be in an English family" (Journal Entry, March 23, 2007).

It made sense that she, too, was observing that other families speak 
Spanish at home and that it would be easier for her to learn at school if Spanish was her native language. This is a pragmatic issue for a child. Yet, the issue of identity may be intertwined and is perhaps the most socially salient. The identity issues that arise from an African American student participating in an immersion program can be complex. One crucial area to address is how the development of cross-cultural attitudes interacts with the student's racial identity.

While the importance of cultural identity and student wellness has been studied, the findings point to a need to explore the experiences and effects on students of color who are not members of a language minority group (DixonRayle \& Myers, 2004; Phinney, 1993; Shrake \& Rhee, 2004). In order for students to develop an affirming "metacultural awareness," they have to be exposed to experiences that help them read a multicultural world in ways that support a positive view of their own culture in relation to other cultures (Adelman Reyes \& Vallone, 2007, p. 8). Adelman Reyes and Vallone argue that further research is indeed needed to determine the effect of immersion classrooms on identity construction of African American preschool.

By the end of the school year, we understood more about the process of second language development and were quite pleased with Joyce Lynn's progression. I had to come to understand that one year in a Spanish immersion preschool will not make a confident speaker. I also had to learn to appreciate her comprehension growth. Joyce Lynn was still shy when "non-school" related Spanish speakers tried to engage her in a conversation, but she would respond correctly to their questions in English. Whenever I would ask her to tell me how to say something in Spanish or ask her to tell me the English words to Spanish song she was singing, she would get frustrated. I thought it was because she did not know what it meant. One day she became frustrated after one of these requests and began to explain to me, "Mommy, Ms. Marta does not tell us what it means in English, only Spanish." That is when it became clear to me that the integration of language and content, like the integration of first language experiences with life experiences, is a much more powerful learning vehicle than mere linguistic translation.

\section{Recommendations}

It is important to share what was learned from this experience for other parents who are considering an early childhood immersion program in a language that is not spoken in the home. First, patience is more than a virtue; it is a stress saver. Children must receive comprehensible linguistic input and then process it, usually during a silent period, before linguistic output can be expected. This is the same process by which they learn their first language, and we need to regain that sense of joy that we had when they uttered their first words in our own mother tongue and celebrate each phase of the developmental process.

Second, the more opportunities that can be provided for children to use 
the language they are learning at home, the better for the parents and for them. This may require that parents learn right alongside their child(ren). It builds their confidence since they are the experts.

Third, parents must develop a support network. Just as with other childcentered activities which require support, it is necessary to tap the gifts of others in the language acquisition process.

Fourth, it is important to encourage and support learning by exposing child(ren) to authentic experiences outside of school with native speakers so they can see the usefulness of the language. (Remember, the domain in which they most use the second language will be outside of the home.)

Fifth, parents should remember that early childhood immersion programs by their nature do not follow a traditional academic model. Because language is learned through context-embedded experiences, more emphasis is placed on authentic learning. Quality second language programs respect the developmental process of not only language learning but of all learning in childhood. This is because learning and language are integrated.

Finally, we would like to make some recommendations specific to African American parents who decide to place their children in Spanish immersion programs. In an effort to support the students' racial identity, African American parents need to balance the exposure to Latino culture with African American cultural appreciation and understanding. If Latino culture is the only heritage celebrated, children could surmise that it is of more value and worth than their own.

African American parents must keep in mind that their child will not only be a cultural minority in the larger society, but a linguistic minority in the classroom. This might intensify the need to promote positive experiences with African American culture in the out-of-school context. They might also find it advantageous to remind school personnel of the need to highlight aspects of African American culture in the immersion classroom. Perhaps they can volunteer to come into the classroom and share aspects of cultural knowledge in much the same way as Moll, Amanti, Neff, and Gonzalez (1992) suggest using the funds of knowledge Latino parents bring and integrating it into the classroom.

In an effort to highlight African American students' culture and heritage within the Spanish language that they are learning in the classroom, families have access to natural resources: Pan African and Afro-Caribbean heritage activities. We did not make use of these heritage groups or activities during Joyce Lynn's first year, but our extensive support group included a few individuals with Afro-Caribbean backgrounds. Spending time with these individuals when they were speaking their native language gave Joyce Lynn an opportunity to see that her heritage and the Spanish language are not mutually exclusive. 


\section{Conclusion}

Throughout our experience with Joyce Lynn we learned firsthand about the issues and benefits of immersion programs. Our concerns were similar to what most parents feel when their children attend school for the first time. However, the language barrier seemed to intensify the issue of home-school communication. On the other hand, benefits included witnessing the development of our daughter's ability to absorb authentic experiences. The foundation of her global perspective may be more inclusive than it would have been otherwise. Overall, we are pleased with her development after her first year in an immersion preschool and will continue to look for opportunities for advancement and use of her language skills.

\section{Notes}

1. Pseudonyms are used to protect the people and places referred to in this article.

2. In the narrative "we" refers to the first author and her husband.

\section{References}

Ada, A. F. (1993). A critical pedagogy approach to fostering the home-school connection. Washington, DC. Retrieved from ERIC database (ED358716)

Adelman Reyes, S. (1998). "IMami, yo toque una mariposa!": An alternative to linguistic and cultural loss. (Unpublished doctoral dissertation). University of Illinois, Chicago.

Adelman Reyes, S., \& Vallone, T. L. (2007). Toward an expanded understanding of two-way bilingual immersion education: Constructing identity through a critical additive bilingual/bicultural pedagogy. Multicultural Perspectives, 9(3), 3-11.

Ajuria, A. (1994). An exploration of classroom activity and student success in a two-way bilingual and a mainstream program. (Unpublished doctoral dissertation). Boston College, Boston.

Castillo, C. (2001). The effects of dual language education program on student achievement and development of leadership abilities. (Unpublished doctoral dissertation). Our Lady of the Lake University, San Antonio, TX.

Cazabon, M., Lambert, W., \& Hall, G. (1993). Two-way bilingual education: A progress report on the amigos program. Santa Cruz, CA and Washington, 
DC: National Center for Research on Cultural Diversity and Second Language Learning.

Collier, V. P. (1989). How long? A synthesis of research on academic achievement in a second language. TESOL Quarterly, 23(3), 509-31.

Collier, V. P., \& Thomas, W. P. (2000). Making U.S. schools effective for English language learners, part 3. TESOL Matters, 9(6), 1-10.

Coy, S., \& Litherland, L. (2000). From a foreign language perspective: A snapshot view of a dual language program in two inner-city high poverty elementary schools. Washington, D.C. Retrieved from ERIC database (ED446450)

Dixon-Rayle, A., \& Myers, J. (2004). Counseling adolescents towards wellness: The roles of ethnic identity, acculturation, and mattering. Professional School Counseling, 8(1), 81-90.

Dolson, D. P. (1985). The application of immersion education in the United States Arlington,VA: National Clearinghouse for Bilingual Education. Retrieved from ERIC database (ED291257)

Fernandez, M. (2006). Bilingual preschoolers: Implications for the development of identity and self concept. Journal of Early Childhood and Infant Psychology, 2, 5-16.

Fishman, J. A., Cooper, R. L., \& Ma, R. (Eds.). (1971). Bilingualism in the barrio. Bloomington, IN: Indiana University Press.

Giacchino-Baker, R., \& Piller, B. (2006). Parental motivation, attitudes, support, and commitment in a Southern Californian two-way immersion program. Journal of Latinos \& Education, 5(1), 5-28.

Gilbert, S. M. (2001). The impact of two-way dual-language programs on fourthgrade students: Academic skills in reading and math, language development, and self-concept development. (Unpublished doctoral dissertation). New Mexico State University, Las Cruces, NM.

Howard, E. R., Sugarman, J., \& Christian, D. (2003). Trends in two-way immersion education: $A$ review of the research (report no. 63). Baltimore, MD: Center for Research on the Education of Students Placed At Risk.

Kirk Senesac, B. V. (2002). Two-way bilingual immersion: A portrait of quality schooling. Bilingual Research Journal, 26(1), 85-101.

Knopf, H. T., \& Swick, K. J. (2007). How parents feel about their child's teacher/school: Implications for early childhood professionals. Early Childhood Education Journal, 34(4), 291-296.

Krashen, S. (1997). The comprehension hypothesis: Recent evidence. English Teachers' Journal (Israel), 51, 17-29.

Lindholm-Leary, K. J. (2005). The rich promise of two-way immersion. Educational Leadership, 62(4), 56-59. 
Lindholm, K., \& Aclan, Z. (1991). Bilingual proficiency as a bridge to academic achievement: Results from bilingual/immersion programs. Journal of Education, 173, 71-80.

Moll, L. C., Amanti, C., Neff, D., \& Gonzalez, N. (1992). Funds of knowledge for teaching: Using a qualitative approach to connect homes and classrooms. Theory into Practice, 31(2), 132-141.

Moore, Z., \& English, M. (1997). Linguistic and cultural comparisons: Middle school African American students learning Arabic. Retrieved from ERIC database (ED414723)

Phinney, J. (1993). A three-stage model of ethnic identity development. In M.G. \& B. Knight (Ed.), Ethnic identity: Foundation and transmission among Hispanics and other minorities (pp. 61-79). Albany: State University of New York.

Postovsky, V. A. (1974). Effects of delay in oral practice at the beginning of second language learning. Modern Language Journal. 58(5-6). 229-239.

Rankin, W. (1998). German language instruction at historically black colleges and universities and the future of German in (African) American higher education. Retrieved from ERIC database (ED419392)

Saville-Troike, M. (1988). Private speech: Second language learning during the "silent" period. Journal of Child Language, 15(3), 567--90.

Sera, G. L. (2000). The nature and English language consequences of dual immersion schooling. (Unpublished doctoral dissertation). Indiana University, Bloomington, IN.

Shrake, E. K., \& Rhee, S. (2004). Ethnic identity as a predictor of problem behaviors among Korean American adolescents. Adolescence, 39(155), 601-22.

Stewart, M., \& Talburt, S. (1999). What's the subject of study abroad?: Race, gender, and living culture. Modern Language Journal, 83(2), 163-175.

Stipek, D., Ryan, R., \& Alarcón, R. (2001). Bridging research and practice to develop a two-way bilingual program. Early Childhood Research Quarterly, 16(1), 133-149.

Swain, M., \& Lapkin, S. (1981). Bilingual education in Ontario: a decade of research. Toronto, Ontario: Toronto Ontario Institute for Studies in Education.

Thomas, W. P., \& Collier, V. P. (2002). A national study of school effectiveness for language minority students' long-term academic achievement. Santa Cruz, CA: Center for Research on Education, Diversity and Excellence. 